\title{
Synergistic Antifungal Activity of Magnoliae Cortex and Syzyii Flos against Candida albicans ${ }^{1}$
}

\author{
Jeemin $\mathrm{YOON}^{2} \cdot$ Tae-Jong $\mathrm{KIM} \oplus^{2, \dagger}$
}

\begin{abstract}
Candida albicans is a dermal fungus of the human body that is known to cause oral candidiasis, vaginal candidiasis, and bloodstream infections in immunocompromised people or in certain environmental conditions. As cases of strains resistant to antifungal agents in $C$. albicans have been reported, studies using plant materials as safe antifungal agents are being actively conducted. In this study, a total of 17 edible plant extracts showed antifungal activity against $C$. albicans as a result of evaluating a 280-plant extract library using paper disk diffusion method. Among them, the four extracts with the strongest antifungal activity (Cinnamomi Cortex, Cinnamomi Ramulus, Magnoliae Cortex, and Syzygii Flos) were selected and evaluated for synergistic antifungal activity against $C$. albicans. The combination of Magnoliae Cortex and Syzygii Flos showed a synergistic activity. The antifungal activity was evaluated based on the concentrations of magnolol and eugenol, the respective components of Magnoliae Cortex and Syzygii Flos. Magnolol and eugenol showed synergistic antifungal activities at the concentration ratio of 1:25 - 1:61. The antifungal activity of these two compounds contributes 28 to $48 \%$ to the synergistic antifungal activity of the combination of Magnoliae Cortex and Syzygii Flos extract. In this study, we propose that a combination of Magnoliae Cortex and Syzygii Flos can effectively inhibit the growth of $C$. albicans and that magnolol and eugenol are the responsible inhibitory compounds.
\end{abstract}

Keywords: candida albicans, magnoliae cortex, syzygii flos, antifungal activity, synergy, magnolol, eugenol

\section{INTRODUCTION}

Candida albicans is a member of normal microbial flora on the human skin (Hedderwick and Kauffman, 1997), but can cause candidiasis (Kumamoto and Vinces, 2005). Candidiasis can cause oral (Epstein, 1990), genital (Donders et al., 2010; Sobel, 2007), and skin infections (Bodey and Luna, 1974) in healthy people, especially in immunocompromised people (Edmond et al., 1999; Jarvis et al., 1991). Candidiasis is the second leading cause of death by infections in hospitals (Sagué et al., 1993).

Antifungal agents used to treat candidiasis belong to the azole family, such as fluconazole, intraconazole, and voriconazole, as well as the polyene family, such as amphotricin B (Garcia-Cuesta et al., 2014). Fluconazole is the most commonly prescribed antifungal agent for C. albicans infections (Pfaller et al., 2010), while amphotericin B is used commonly for the treatment of many fungal infections (Sugar et al., 1995). However,

\footnotetext{
${ }^{1}$ Date Received January 8, 2021, Date Accepted February 10, 2021

2 Department of Forest Products and Biotechnology, Kookmin University, Seoul 02707, Republic of Korea

$\dagger$ Corresponding author: Tae-Jong KIM (e-mail: bigbell@kookmin.ac.kr, ORCID: 0000-0002-7483-0432)
} 
strains resistant to fluconazole and itraconazole have been reported. (Xiang et al., 2013; Zhao et al., 2013), while amphotricin $\mathrm{B}$ has been reported to exhibit renal toxicity (Fanos and Cataldi, 2000).

Therefore, new alternative agents with excellent antifungal activity and less side effects are required. However, due to structural and functional similarities between fungal and human cells, it is difficult to develop an antifungal agent without side effects (Blaszczyk et al., 2000). Previous studies have shown the antifungal activity of extracts of Cinnamomum parthenoxylon (Adfa et al., 2020) and Abies holophylla (Kim et al., 2016). Antifungal activity compounds have also been reported in Pestalotiopsis theae and Curvularia sp. isolated from woods (Hidaya et al., 2019). Edible plants are recognized to be less toxic. Many edible plants have been reported for their antifungal activities against C. albicans (Bais et al., 2013; de Toledo et al., 2011; Duarte et al., 2005; Vaijayanthimala et al., 2000).

Magnoliae Cortex is the stem bark of Magnolia ovobata Thunb. It has been reported to exhibit anti-inflammatory (Lee et al., 2005), anti-microbial (Ho et al., 2001; Sakaue et al., 2016), and antioxidant activity (Shen et al., 2010). Syzygii Flos, known as clove, is the flower bud of Syzygium aromaticum. Clove is used as a spice in many countries and has been used to remove bad breath for a long time (Bhowmik et al., 2012). Clove has been reported to have various medical effects, such as antioxidant (Lee and Shibamoto, 2001; Shobana and Akhilender Naidu, 2000), anti-cancer (Liu et al., 2014), and anti-stress effect (Singh et al., 2009). Clove is also known to be effective in killing bacteria (Cai, 1996; Lee and Son, 2006) and fungi (Silva et al., 2017).

Many studies have been conducted to reduce the amount of antifungal agents used through synergistic activities by mixing plant compounds. The addition of plant antifungal compounds was known for many ben- efits such as antifungal efficacy against a wide range of fungi, increased safety, reduced toxicity, and reduced antifungal resistance. The synergistic effect of the combination of two substances is useful and effective because it can increase antifungal activities (Mukherjee et al., 2005). Another benefit of synergistic combination is the complementary action, because each compounds can have different growth inhibitory mechanisms which complement each other (Wagner and Ulrich-Merzenich, 2009).

In this study, the synergistic antifungal activity of Magnoliae Cortex and Syzyii Flos against $C$. albicans was demonstrated and confirmed that their major components, magnolol and eugenol, respectively, contribute to this synergistic antifungal activity.

\section{MATERIALS and METHODS}

\subsection{Plants extracts, strain, and medium}

Plants and their extracts library were prepared in the previous study (Ham and Kim, 2018). Candida albicans KCTC 7965 was purchased from Korean Collection for Type Cultures in Korea Research Institute of Bioscience and Biotechnology (Jeongeup, Korea) and stored at $-80^{\circ} \mathrm{C}$ in a mixture with $15 \%$ glycerol. YPD medium was made with $1 \%$ yeast extract, $2 \%$ peptone, and $2 \%$ dextrose. YPD plate was made with YPD medium and $1.5 \%$ agar. SDA plate was made with $3 \%$ Sabouraud Dextrose Broth (catalog number: BD 238230, Becton, Dickinson and Company, Franklin Lakes, NJ, USA) and 1.5\% agar. RPMI-1640 medium was made with $1.04 \%$ RPMI-1640 medium (catalog number: R6504, Merck KGaA, Darmstadt, Germany) and $0.165 \mathrm{M}$ 3-(N-morpholino)propanesulfonic acid as a buffer. The analytical standards, eugenol (catalog number: E51791) and magnolol (catalog number: D3971), were purchased from Sigma-Aldrich Co., Inc. (St. Louis, MO, United States) and Tokyo Chemical Industry Co., Ltd. (Tokyo, Japan), respectively. 


\subsection{Measurement of growth inhibition zone by plant extracts}

Each extract of $50 \mathrm{mg}$ was dissolved in $1 \mathrm{~mL}$ of methanol and incubated at $50^{\circ} \mathrm{C}$ for $5 \mathrm{~min}$. After vortexing, the dissolved extract sample was centrifuged at $13,000 \mathrm{rpm}$ for $10 \mathrm{~min}$. The transparent supernatant was used for further experiments. The supernatant with $20 \mu \mathrm{L}$ was loaded 5 times onto paper disc (Catalog number: 49005040, Advantec MFS, Inc., Dublin, CA, USA) and dried. As a control, $20 \mu \mathrm{L}$ of methanol, the solvent in which the extract was dissolved, was loaded 5 times and dried.

C. albicans stored at $-80^{\circ} \mathrm{C}$ were inoculated on YPD plates and incubated at $26^{\circ} \mathrm{C}$ for 2 days. A single colony was incubated in $5 \mathrm{~mL}$ of YPD medium and incubated at $26^{\circ} \mathrm{C}$ and $250 \mathrm{rpm}$ for 1 day. Absorbance of the pre-cultured cells was measured and diluted with YPD medium to make the concentration of the initial cells $\left(\mathrm{Abs}_{600}=1\right)$. After the diluted cells with $0.1 \mathrm{~mL}$ was spread on YPD plate, a paper disc with an extract was placed in the center of the plates and incubated at $26^{\circ} \mathrm{C}$ for 1 days. After incubation, it was judged that an extract having a growth inhibition zone more than $1 \mathrm{~mm}$ around the paper had an antifungal activity. The experiments were repeated 3 times per extract and the average value showing the diameter of the growth-inhibiting zone with the standard deviation was calculated.

\subsection{Measurement of the growth inhibition of $C$. albicans in YPD medium}

After the transparent sample solution was prepared by the method described in the previous paragraph, it was diluted according to the test concentration and $50 \mu \mathrm{L}$ of the diluted sample was mixed in $5 \mathrm{~mL}$ of YPD medium. The control YPD medium was treated with $50 \mu \mathrm{L}$ of methanol. The pre-cultured C. albicans was inoculated to have an $\mathrm{Abs}_{600}$ value of 0.05 and then cultured at $26^{\circ} \mathrm{C}$ and $250 \mathrm{rpm}$ for 18 hours. The cell concentration was measured with a spectrophotometer (Optizen 2120UV, Mecasys Co., Ltd., Daejeon, Korea) at an absorbance of $600 \mathrm{~nm}$. The relative growth was calculated by comparing the cell growth to the control.

\subsection{Evaluation of synergistic growth inhibition in a liquid culture}

In order to evaluate the synergistic effect of the selected extracts, sample concentrations that inhibited the growth of $C$. albicans by $20 \%$ were determined. The determined concentrations for extracts are presented in the result section. Extracts at the indicated concentrations were prepared by mixing $50 \mu \mathrm{L}$ of one extract and $50 \mu \mathrm{L}$ of the other extract in $5 \mathrm{~mL}$ of YPD medium. The control group was treated with 100 $\mu \mathrm{L}$ of $99.5 \%$ methanol, the solvent in which the extract was dissolved. Three different control cultures were used: culture with $100 \mu \mathrm{L}$ of methanol; culture with $50 \mu \mathrm{L}$ of the first extract; and culture with 50 $\mu \mathrm{L}$ of the other extract. The pre-cultured C. albicans was inoculated to have an $\mathrm{Abs}_{600}$ value of 0.05 and then cultured at $26^{\circ} \mathrm{C}$ and $250 \mathrm{rpm}$ for 18 hours. The cell concentration of the culture medium was measured with a spectrophotometer (Optizen 2120UV). Relative growth was calculated and compared to the cell growth of the control.

\subsection{Evaluation of synergistic growth inhibition by checker board method}

To measure the antifungal activity on $C$. albicans, CLSI M27-A2 broth microdilution methods (NCCLS, 2002) using checkerboard combinations was employed. C. albicans stored at $-80^{\circ} \mathrm{C}$ were streaked on SDA plates and incubated at $35^{\circ} \mathrm{C}$ for 1 day. A single colony was suspended in $0.145 \mathrm{~mol} / \mathrm{L}$ saline and vortexed for 15 seconds. The suspended colony was measured 
by absorbance at a wavelength of $530 \mathrm{~nm}$ with a spectrophotometer (Optizen 2120UV) and adjusted with saline to 0.5 McFarland turbidity in order to prepare a $C$. albicans suspension. The inoculated concentration of $C$. albicans in the culture for measuring the antifungal activity was $1 \times 10^{3} \sim 5 \times 10^{3} \mathrm{CFU} / \mathrm{mL}$. Both tested extracts were dissolved separately in RPMI 1640 medium. Two dissolved extracts were mixed in $50 \mu \mathrm{L}$ each. As a control, $50 \mu \mathrm{L}$ of each sample and $50 \mu \mathrm{L}$ of RPMI 1640 medium were used. After inoculation, cells were incubated at $35^{\circ} \mathrm{C}$ for 2 days. The sunk cells were suspended by pipetting and cell turbidity of wells was measured at $530 \mathrm{~nm}$ with a microplate reader (Synergy LX, BioTek Instruments, Inc., Winooski, VT, USA).

Growth inhibition (GI \%) was calculated by the equation stated below. The cell density was measured by absorbance at a wavelength of $530 \mathrm{~nm}$ with a spectrophotometer.

GI $(\%)=($ Cell density of control - Cell density of sample) $/$ Cell density of control $\times 100$

Compared with the antifungal activity as GI \% of each treatment, it was judged that there was a synergistic antifungal activity when the antifungal activity of the mixture were 2 times or more than individual two treatments (Chusri et al., 2014).

\subsection{Quantitative analysis of eugenol and magnolol by high-performance liquid chromatography}

High-performance liquid chromatography used for the analysis of eugenol and magnolol was composed with vacuum degasser \& mixer (catalog number: SDV40A), gradient column oven (catalog number: CTS30), auto-sampler (catalog number: YL9150 Alias), solvent delivery pump (catalog number: SP930D), and $\mathrm{UV} /$ Vis detector with dual wavelength (catalog number: YL9120) from YL Instruments Co., Ltd. (Anyang,
Korea).

YMC-Triart C18 (catalog number: TA12S05-2546WT, YMC Korea Co., Ltd, Seongnam, Korea) was used for the analytic column. All samples were filtered with SEPARA syringeless filter vial (catalog number: MV32ANPPV002FC01, GVS North America, Inc., Sanford, ME, USA) prior to analysis. Results were analyzed with Autochro-3000 software (version 2.0.0) program from YL Instruments Co., Ltd.

The operating conditions for the analysis of eugenol were the same as those of a previous study (Seal, 2016). The mobile phase was acetonitrile (solvent A) and $1 \%(\mathrm{v} / \mathrm{v})$ acetic acid (solvent $\mathrm{B})$. The solvent ratio (solvent A : solvent B) was 10:90 at 0 minute, 40:60 at 28 minute, $60: 40$ at 39 minute, $90: 10$ at 50 minute, 10:90 at 55 minute, and 10:90 at 65 minute. The wavelength for eugenol analysis was $272 \mathrm{~nm}$, speed of the mobile phase was $0.7 \mathrm{~mL} / \mathrm{min}$, column temperature was $28^{\circ} \mathrm{C}$, and analysis time was 65 minutes.

The conditions for the magnolol analysis were the same as those of a previous study (Kim and Kim, 2004). The mobile phase for magnolol was acetonitrile and $2 \%(\mathrm{v} / \mathrm{v})$ acetic acid, at the ration of 50:50. The analysis conditions for magnolol were $289 \mathrm{~nm}$ of wavelength for detection, $1 \mathrm{~mL} / \mathrm{min}$ for speed of the mobile phase, $26^{\circ} \mathrm{C}$ for column temperature, and 60 minutes for analysis time.

\section{RESULTS and DISCUSSION}

\subsection{Antifungal activity of four plant extracts}

Antifungal activity against $C$. albicans was measured by disk diffusion test using a methanol extract library of 280 edible plants listed in the Korean Pharmacopoeia or Herbal/Korean Traditional Products from National Institute of Food and Drug Safety Evaluation. The growth inhibition activity of 17 se- 
lected plant extracts is shown in Table 1. The size of the clear zone was $34.8 \mathrm{~mm}$ by Cinnamomi Cortex, $19.8 \mathrm{~mm}$ by Cinnamomi Ramulus, $19.8 \mathrm{~mm}$ by Magnoliae Cortex, and $16.8 \mathrm{~mm}$ by Syzygii Flos. The antifungal effect according to the concentration was observed in four plant extracts, with a diameter of $\geq$ $15 \mathrm{~mm}$ in the inhibition area (Fig. 1). Three plant extracts, Cinnamomi Cortex (Fig. 1A), Magnoliae Cortex (Fig. 1C), and Syzygii Flos (Fig. 1D), showed $\geq 78 \%$ growth inhibitory activity against $C$. albicans at a concentration of $0.5 \mathrm{~g} / \mathrm{L}$. Cinnamomi Cortex and Cinnamomi Ramulus is a bark and young branch, respectively, of Cinnamomum cassia Presl. However, the growth inhibitory effect of Cinnamomi Ramulus extract on $C$. albicans was much less than that of Cinnamomi

Table 1. Antifungal activity of 17 plant extracts on the growth of $C$. albicans. The diameter of growth inhibited zones is an average and standard deviation of three samples

\begin{tabular}{cc}
\hline Plant used for extracts & $\begin{array}{c}\text { Diameter of growth } \\
\text { inhibited zone }(\mathrm{mm})\end{array}$ \\
\hline \hline Control & $0.0 \pm 0.0$ \\
Acori Gramineri Rhizoma & $7.0 \pm 0.0$ \\
Amomi Tsao-ko Fructus & $8.0 \pm 0.0$ \\
Angelicae Tenuissimae Radix & $8.8 \pm 0.4$ \\
Cinnamomi Cortex & $34.8 \pm 2.4$ \\
Cinnamomi Ramulus & $19.8 \pm 1.7$ \\
Cnidii Rhizoma & $9.0 \pm 0.0$ \\
Cocculi Radix & $9.3 \pm 1.4$ \\
Flower of Rosa multiflora & $8.2 \pm 0.4$ \\
Impatientis Semen & $14.8 \pm 0.4$ \\
Magnoliae Cortex & $19.8 \pm 1.5$ \\
Moutan Cortex Radicis & $12.2 \pm 0.8$ \\
Phellodendri Cortex & $7.3 \pm 0.3$ \\
Polygalae Radix & $9.3 \pm 0.5$ \\
Rhizome of Kaempferia galangal & $7.3 \pm 0.5$ \\
Sanguisorbae Radix & $8.0 \pm 0.0$ \\
Scutellariae Radix & $7.5 \pm 0.0$ \\
Syzygii Flos & $16.8 \pm 1.01$ \\
\hline
\end{tabular}

Cortex extract. Cinnamomi Cortex extract showed no cell growth at $0.5 \mathrm{~g} / \mathrm{L}$. trans-Cinnamaldehyde as an antifungal compound from Cinnamomi Cortex inhibited chitin synthases, the cell wall synthesizing enzymes of Saccharomyces cerevisiae, in vitro (Bang et al., 2000a). Cinnamaldehyde was reported to be an antifungal chemical in Cinnamomi Ramulus (Wan et al., 2017). Magnolol and honokiol from Magnoliae Cortex inhibited the growth of seven pathogenic fungi (Chen et al., 2019) and magnolol had a synergistic antifungal activity with azoles against C. albicans (Sun et al., 2015). Eugenol from Syzygii Flos synergistically inhibited the growth of $C$. albicans with nystatin (Silva et al., 2017). A chemical-genetic profile analysis suggested that eugenol interfered with two permeases for the transport of aromatic and branched chain amino acids in the cytoplasmic membrane of $S$. cerevisiae (Darvishi et al., 2013).
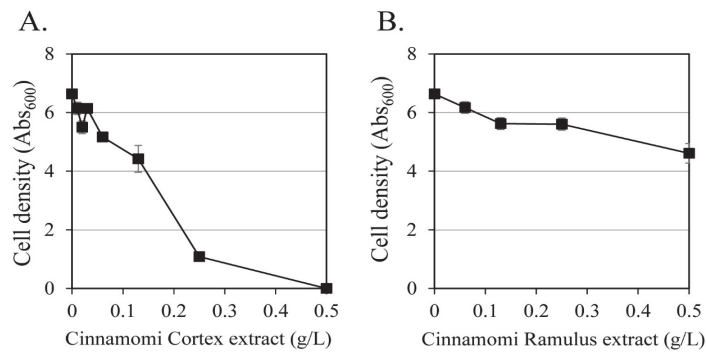

C.

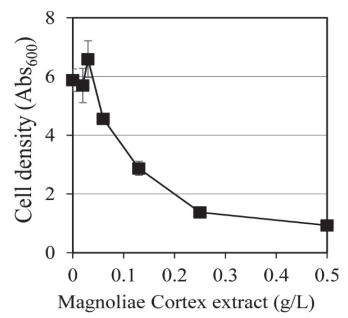

D.

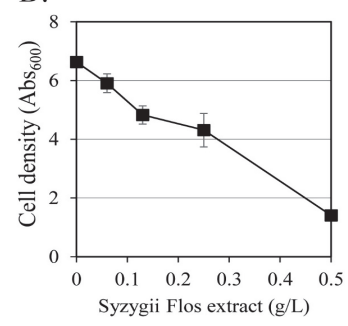

Fig. 1. Antifungal activity against $C$. albicans according to the concentration of the selected four plant extracts, (A) Cinnamomi Cortex extract, (B) Cinnamomi Ramulus extract, (C) Magnoliae Cortex extract, and (D) Syzygii Flos extract. The values are average of three independent experiments. 


\subsection{Synergistic antifungal activity of Magnoliae Cortex and Syzygii Flos extract}

Synergistic growth inhibitory effect on C. albicans was tested using a mixture of two extracts among the four tested extracts in Fig. 1 (Fig. 2). The test concentration of the four selected extracts in Fig. 2 were determined to have GI $20 \%$ activity from Fig. 1, with $0.06 \mathrm{~g} / \mathrm{L}$ for Cinnamomi Cortex, $0.3 \mathrm{~g} / \mathrm{L}$ for Cinnamomi Ramulus, $0.06 \mathrm{~g} / \mathrm{L}$ for Magnoliae Cortex, and $0.12 \mathrm{~g} / \mathrm{L}$ for Syzygii Flos. Inhibitory activity against the growth of $C$. albicans was measured for six combinations of four selected plant extracts. Although the five combi-

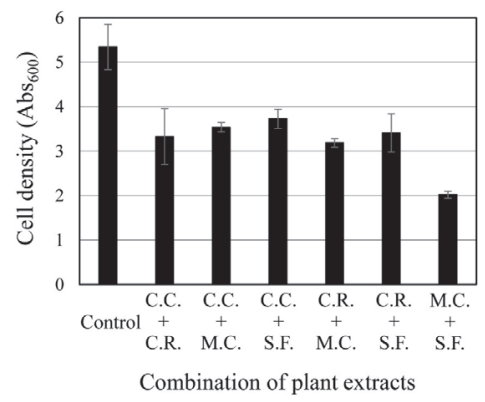

Fig. 2. Antifungal activity of combination of two antifungal plant extracts against $C$. albicans. C.C.: Cinnamomi Cortex extract (0.06 g/L); C.R.: Cinnamomi Ramulus extract $(0.3 \mathrm{~g} / \mathrm{L})$; M.C.: Magnoliae Cortex extract $(0.06 \mathrm{~g} / \mathrm{L})$; S.F.: Syzygii Flos extract $(0.12 \mathrm{~g} / \mathrm{L})$. The values are average of three independent experiments.
A.

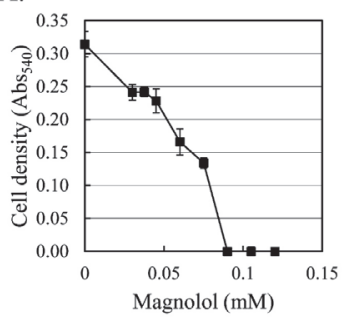

B.

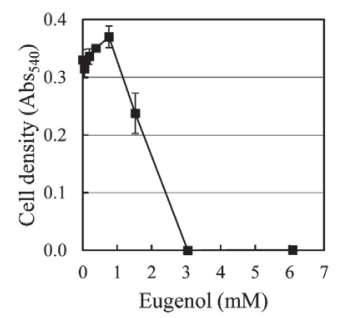

Fig. 3. Antifungal activity of magnolol and eugenol against $C$. albicans. The values are average of six independent experiments. nations showed just the sum of their respective inhibitory effects, the combination of Magnoliae Cortex extract and Syzygii Flos extract showed $\geq$ GI $60 \%$. The inhibitory activity above the sum of their respective inhibitory effects suggest a synergistic effect by mixing the two tested extracts.

\subsection{Growth inhibition of $C$. albicans by magnolol and eugenol}

Magnolol is known as an antifungal compound in Magnoliae Cortex against C. albicans (Chen et al., 2019; Sun et al., 2015) and eugenol is an antifungal compound in Syzygii Flos extract (Darvishi et al., 2013). Using a high-performance liquid chromatography analysis, the Magnoliae Cortex extract contained $6.44 \%$ magnolol, with a retention time of about 41.1 min, while Syzygii Flos extract contained $56.68 \%$ eugenol, with a retention time of about $49.8 \mathrm{~min}$.

Both magnolol and eugenol, the assay standard compounds, inhibited the growth of $C$. albicans (Fig. $3)$. The growth inhibitory effect was shown in proportion to the concentration of magnolol and C. albicans growth was completely suppressed by magnolol in concentrations $\geq 0.09 \mathrm{mM}(24 \mathrm{mg} / \mathrm{L})$ (Fig. 3A). This result is consistent with the inhibitory concentration of magnolol on the biofilm formation of $C$. albicans in a previous study (Zhou et al., 2017).

Eugenol did not inhibit the growth of $C$. albicans until $0.76 \mathrm{mM}(0.125 \mathrm{~g} / \mathrm{L})$, but showed complete inhibition at concentrations above $3.05 \mathrm{mM}(0.5 \mathrm{~g} / \mathrm{L})$ (Fig. 3B). This result is twice the value of $0.25 \mathrm{~g} / \mathrm{L}$ in planktonic growth of C. albicans (Tampieri et al., 2005) and is consistent with the minimal inhibitory concentration of $0.5 \mathrm{~g} / \mathrm{L}$ for sessile C. albicans in a previous study (He et al., 2007). The main component of Syzygii Flos is eugenol (Pinto et al., 2009) and the antifungal activity of eugenol on fungi other than $C$. albicans have been reported in previous studies (Chami et al., 2004; Cheng et al., 2008; de Oliveira 
Pereira et al., 2013). The antifungal activity of magnolol against $C$. albicans was about 34 times stronger than that of eugenol.

\subsection{Synergistic inhibition of magnolol and eugenol on growth of $C$. albicans}

To test the synergistic growth inhibition of magnolol and eugenol, a checker board experiment was performed at various concentrations of magnolol (0-24 $\mathrm{mg} / \mathrm{L})$ and eugenol $\left(0^{-}-0.3 \mathrm{~g} / \mathrm{L}\right)$. The synergistic concentration range was determined to have more than twice the inhibitory activity of all the results of the individual compounds. The synergistic growth inhibitory concentration range was $8-24 \mathrm{mg} / \mathrm{L}$ for magnolol and $0.25-0.3 \mathrm{~g} / \mathrm{L}$ for eugenol. The concentration ratio of magnolol and eugenol for the synergistic inhibitory activity was 1:25-1:61.

Considering the content of magnolol in Magnoliae Cortex and eugenol in Syzygii Flos extract, the antifungal activity on $C$. albicans by combination of mag-

Table 2. The growth inhibition of $C$. albicans by combination of eugenol and magnolol. The synergistic growth inhibition is indicated in bold. Growth inhibition was calculated by comparing the cell density $\left(\mathrm{Abs}_{595}\right)$ at the indicated eugenol and magnolol concentrations to the cell density without eugenol and magnolol $\left(\mathrm{Abs}_{595}\right)$. The statistical analysis was performed by one-way ANOVA using Tukey method. Values that differ from the control at a $95 \%$ confidence level are marked with a star on top of symbols

\begin{tabular}{cc|cccc}
\hline & \multicolumn{4}{|c}{ Eugenol $(\mathrm{mg} / \mathrm{L})$} \\
& & 0 & 125 & 250 & 300 \\
\hline \hline & 0 & $0.0 \%$ & $0.0 \%$ & $12.1 \%$ & $14.2 \%$ \\
& 4 & $2.9 \%$ & $2.1 \%$ & $28.5 \%$ & $31.1 \%$ \\
Magnolol & 10 & $20.9 \%$ & $15.0 \%$ & $\mathbf{4 4 . 7 \%}$ & $\mathbf{4 5 . 6 \%}$ \\
$(\mathrm{mg} / \mathrm{L})$ & $21.1 \%$ & $25.6 \%$ & $\mathbf{5 0 . 9 \%}$ & $\mathbf{5 5 . 8 \%}$ \\
& 12 & $20.7 \%$ & $26.9 \%$ & $\mathbf{5 3 . 8 \%}$ & $\mathbf{5 9 . 7 \%}$ \\
& 16 & $35.3 \%$ & $41.6 \%$ & $\mathbf{7 1 . 4 \%}$ & $\mathbf{7 7 . 9 \%}$ \\
& 24 & $54.4 \%$ & $60.4 \%$ & $100.0 \%$ & $100.0 \%$ \\
\hline
\end{tabular}

nolol and eugenol was estimated to contribute $28-48 \%$ of the antifungal activity by combination of Magnoliae Cortex extract and Syzygii Flos extract. This estimated value suggests that there are additional compounds with antifungal activity in addition to magnolol and eugenol in the Magnoliae Cortex and Syzygii Flos extract, respectively. In a previous study, it was reported that honokiol and obovatol, in addition to magnolol, were chemical components present in Magnoliae Cortex (Shen et al., 2009). Honokiol had an antifungal activity on C. albicans (Bang et al., 2000b). Obovatols inhibited the cell wall synthesis of $S$. cerevisiae (Hwang et al., 2002). In addition to eugenol, Syzygii Flos had phenolic compounds (Shan et al., 2005) and these phenolic compounds, including caffeic acid (Ma and Ma, 2015), ferulic acid (Shi et al., 2016), elagic acid (Li et al., 2015), and salicylic acids (Amborabé et al., 2002), showed antifungal activities.

With the recent increase in reports of azole resistance of C. albicans (Whaley et al., 2017), it has become very important to discover and develop new antifungal compounds, as well as reduce the use of antifungal agents by mixing antifungal agents. Moreover, synergistic antifungal activities had been reported in previous studies, such as oil from Ocimum basilicum var. Maria Bonita with fluconazole (Cardoso et al., 2016), ethanolic extract of the leaves of Ocimium gratisimum L. with ketoconazole and nystatin (Nweze and Eze, 2009), Melaleuca alternifolia, Origanum vulgare, and Pelargonium graveolens essential oils with amphotericin B (Rosato et al., 2008), and thionin-like peptide from Capsicum annum fruits with fluconazole (Taveira et al., 2016). In this study, the synergistic action between the extracts of Magnoliae Cortex and extract of Syzygii Flos was suggested. In this study, we proposed an antifungal treatment that utilizes increased antifungal activity while minimizing the amount of use by combining only plant extracts without using antifungal compounds. 


\section{CONCLUSION}

As agents to inhibit the growth of $C$. albicans, which causes candidiasis, 17 edible plant extracts were identified. Among the four extracts with a high antifungal activity, a combination of Magnoliae Cortex and Syzyii Flos, whose antifungal effect was increased synergistically, is proposed as an agent for effectively eliminating $C$. albicans. The antifungal activity of this combination is explained by magnolol and eugenol partially and the presence of additional antifungal compounds was suggested. The results of this study propose a new safe method of using plant extracts for the treatment of candidiasis.

\section{ACKNOWLEDGMENT}

This study was carried out with the support of 'R\&D Program for Forest Science Technology (Project No. 2019150B10-2123-0301)' provided by Korea Forest Service (Korea Forestry Promotion Institute).

\section{REFERENCES}

Adfa, M., Romayasa, A., Kusnanda, A.J., Avidlyandi, A., Yudha, S., Banon, C., Gustian, I. 2020. Chemical components, antitermite and antifungal activities of Cinnamomum parthenoxylon wood vinegar. Journal of the Korean Wood Science and Technology 48(1): 107-116.

Amborabé, B.-E., Fleurat-Lessard, P., Chollet, J.-F., Roblin, G. 2002. Antifungal effects of salicylic acid and other benzoic acid derivatives towards Eutypa lata: structure-activity relationship. Plant Physiology and Biochemistry 40(12): 1051-1060.

Bais, Y., Chaudhari, S.B., Belani, S., Umakar, A.R. 2013. Evaluation of antimicrobial activity of plant leaf Argemone mexicana. International Journal of Pharmacy and Biological Sciences 3(1): 41-45.
Bang, K.-H., Lee, D.-W., Park, H.-M., Rhee, Y.-H. 2000a. Inhibition of fungal cell wall synthesizing enzymes by trans-cinnamaldehyde. Bioscience, Biotechnology, and Biochemistry 64(5): 1061-1063.

Bang, K.H., Kim, Y.K., Min, B.S., Na, M.K., Rhee, Y.H., Lee, J.P., Bae, K.H. 2000b. Antifungal activity of magnolol and honokiol. Archives of Pharmacal Research 23(1): 46-49.

Bhowmik, D., Kumar, K.P.S., Yadav, A., Srivastava, S., Paswan, S., Dutta, A.S. 2012. Recent trends in Indian traditional herbs Syzygium aromaticum and its health benefits. Journal of Pharmacognosy and Phytochemistry 1(1): 13-22.

Blaszczyk, T., Krzyzanowska, J., Lamer-Zarawska, E. 2000. Screening for antimycotic properties of 56 traditional Chinese drugs. Phytotherapy Research 14(3): 210-212.

Bodey, G.P., Luna, M. 1974. Skin lesions associated with disseminated candidiasis. JAMA 229(11): 1466-1468.

Cai, L. 1996. Compounds from Syzygium aromaticum possessing growth inhibitory activity against oral pathogens. Journal of Natural Products 59(10): 987-990.

Cardoso, N.N.R., Alviano, C.S., Blank, A.F., Romanos, M.T.V., Fonseca, B.B., Rozental, S., Rodrigues, I.A., Alviano, D.S. 2016. Synergism effect of the essential oil from Ocimum basilicum var. Maria Bonita and its major components with fluconazole and its influence on ergosterol biosynthesis. Evidence-Based Complementary and Alternative Medicine 2016(Article ID 5647182).

Chami, F., Chami, N., Bennis, S., Trouillas, J., Remmal, A. 2004. Evaluation of carvacrol and eugenol as prophylaxis and treatment of vaginal candidiasis in an immunosuppressed rat model. Journal of Antimicrobial Chemotherapy 54(5): 909-914.

Chen, Y.-H., Lu, M.-H., Guo, D.-S., Zhai, Y.-Y., Miao, D., Yue, J.-Y., Yuan, C.-H., Zhao, M.-M., An, D.-R 
2019. Antifungal effect of magnolol and honokiol from Magnolia officinalis on Alternaria alternata causing tobacco brown spot. Molecules (Basel, Switzerland) 24(11): 2140.

Cheng, S.-S., Liu, J.-Y., Chang, E.-H., Chang, S.-T. 2008. Antifungal activity of cinnamaldehyde and eugenol congeners against wood-rot fungi. Bioresource Technology 99(11): 5145-5149.

Chusri, S., Siriyong, T., Na-Phatthalung, P., Voravuthikunchai, S.P. 2014. Synergistic effects of ethnomedicinal plants of Apocynaceae family and antibiotics against clinical isolates of Acinetobacter baumannii. Asian Pacific Journal of Tropical Medicine 7(6): 456-461.

Darvishi, E., Omidi, M., Bushehri, A.A.S., Golshani, A., Smith, M.L. 2013. The antifungal eugenol perturbs dual aromatic and branched-chain amino acid permeases in the cytoplasmic membrane of yeast. PloS ONE 8(10): e76028-e76028.

de Oliveira Pereira, F., Mendes, J.M., de Oliveira Lima, E. 2013. Investigation on mechanism of antifungal activity of eugenol against Trichophyton rubrum. Medical Mycology 51(5): 507-513.

de Toledo, C.E.M., Britta, E.A., Ceole, L.F., Silva, E.R., de Mello, J.C.P., Dias Filho, B.P., Nakamura, C.V., Ueda-Nakamura, T. 2011. Antimicrobial and cytotoxic activities of medicinal plants of the Brazilian cerrado, using Brazilian cachaça as extractor liquid. Journal of Ethnopharmacology 133(2): 420-425.

Donders, G., Bellen, G., Mendling, W. 2010. Management of recurrent vulvo-vaginal candidosis as a chronic illness. Gynecologic and Obstetric Investigation 70(4): 306-321.

Duarte, M.C.T., Figueira, G.M., Sartoratto, A., Rehder, V.L.G., Delarmelina, C. 2005. Anti-Candida activity of Brazilian medicinal plants. Journal of ethnopharmacology 97(2): 305-311.

Edmond, M.B., Wallace, S.E., McClish, D.K., Pfaller,
M.A., Jones, R.N., Wenzel, R.P. 1999. Nosocomial bloodstream infections in United States hospitals: A three-year analysis. Clinical Infectious Diseases 29(2): 239-244.

Epstein, J.B. 1990. Antifungal therapy in oropharyngeal mycotic infections. Oral Surgery, Oral Medicine, Oral Pathology 69(1): 32-41.

Fanos, V., Cataldi, L. 2000. Amphotericin B-induced nephrotoxicity: A review. Journal of Chemotherapy 12(6): 463-470.

Garcia-Cuesta, C., Sarrion-Pérez, M.-G., Bagán, J.V. 2014. Current treatment of oral candidiasis: A literature review. Journal of Clinical and Experimental Dentistry 6(5): e576-e582.

Ham, Y., Kim, T.-J. 2018. Plant extracts inhibiting biofilm formation by Streptococcus mutans without antibiotic activity. Journal of the Korean Wood Science and Technology 46(6): 692-702.

He, M., Du, M., Fan, M., Bian, Z. 2007. In vitro activity of eugenol against Candida albicans biofilms. Mycopathologia 163(3): 137-143.

Hedderwick, S., Kauffman, C. 1997. Opportunistic fungal infections: superficial and systemic candidiasis. Geriatrics 52(10): 50-54.

Hidaya, A., Turjaman, M., Faulina, S.A., Ridwan, F., Aryanto, Najmulah, Irawadi, T.T., Iswanto, A.H. 2019. Antioxidant and antifungal activity of endophytic fungi associated with agarwood trees. Journal of the Korean Wood Science and Technology 47(4): 459-471.

Ho, K.-Y., Tsai, C.-C., Chen, C.-P., Huang, J.-S., Lin, C.-C. 2001. Antimicrobial activity of honokiol and magnolol isolated from Magnolia officinalis. Phytotherapy Research 15(2): 139-141.

Hwang, E.-I., Kwon, B.-M., Lee, S.-H., Kim, N.-R., Kang, T.-H., Kim, Y.-T., Park, B.-K., Kim, S.-U. 2002. Obovatols, new chitin synthase 2 inhibitors of Saccharomyces cerevisiae from Magnolia obovata. Journal of Antimicrobial Chemotherapy 49(1): 95-101. 
NCCLS. 2002. Reference method for broth dilution antifungal susceptibility testing of yeasts; Approved standard-2nd ed., NCCLS document M27-A2 (ISBN 1-56238-469-4). NCCLS, 940 West Valley Road, Suite 1400, Wayne, Pennsylvania 19087-1898 USA. Jarvis, W.R., Edwards, J.R., Culver, D.H., Hughes, J.M., Horan, T., Emori, T.G., Banerjee, S., Tolson, J., Henderson, T., Gaynes, R.P., Martone, W.J., National Nosocomial Infections Surveillance System. 1991. Nosocomial infection rates in adult and pediatric intensive care units in the United States. The American Journal of Medicine 91(3): S185-S191.

Kim, K.-S., Kim, H. 2004. Analytical method for the determination of standard compounds in oriental medicine materials listed in the Korean pharmacopoeia (KPVIII). Korean Journal of Crop Science 49(spc1): 117-145.

Kim, S.H., Lee, S.Y., Cho, S.M., Hong, C.Y., Park, M.J., Choi, I.G. 2016. Evaluation on anti-fungal activity and synergy effects of essential oil and their constituents from Abies holophylla. Journal of the Korean Wood Science and Technology 44(1): 113-123.

Kumamoto, C.A., Vinces, M.D. 2005. Alternative Candida albicans lifestyles: growth on surfaces. Annual Review of Microbiology 59(1): 113-133.

Lee, J., Jung, E., Park, J., Jung, K., Lee, S., Hong, S., Park, J., Park, E., Kim, J., Park, S., Park, D. 2005. Anti-inflammatory effects of magnolol and honokiol are mediated through inhibition of the downstream pathway of MEKK-1 in NF- $\kappa$ B activation signaling. Planta Medica 71(04): 338-343.

Lee, K.-G., Shibamoto, T. 2001. Antioxidant property of aroma extract isolated from clove buds [Syzygium aromaticum (L.) Merr. et Perry]. Food Chemistry 74(4): 443-448.

Lee, O.H., Son, J.Y. 2006. Antimicrobial activity of clove extract by extraction solvents. Journal of The
Korean Society of Food Science and Nutrition 33(3): 494-499.

Li, Z.-J., Guo, X., Dawuti, G., Aibai, S. 2015. Antifungal activity of ellagic acid in vitro and in vivo. Phytotherapy Research 29(7): 1019-1025.

Liu, H., Schmitz, J.C., Wei, J., Cao, S., Beumer, J.H., Strychor, S., Cheng, L., Liu, M., Wang, C., Wu, N., Zhao, X., Zhang, Y., Liao, J., Chu, E., Lin, X. 2014. Clove extract inhibits tumor growth and promotes cell cycle arrest and apoptosis. Oncology Research 21(5): 247-259.

Ma, J.-N., Ma, C.-M. 2015. Chapter 71-Antifungal inhibitory activities of caffeic and quinic acid derivatives, in: Preedy, V. R., (Ed.), Coffee in Health and Disease Prevention, Academic Press, San Diego 2015, pp. 635-641.

Mukherjee, P.K., Sheehan, D.J., Hitchcock, C.A., Ghannoum, M.A. 2005. Combination treatment of invasive fungal infections. Clinical Microbiology Reviews 18(1): 163-194.

Nweze, E.I., Eze, E.E. 2009. Justification for the use of Ocimum gratissimum $\mathrm{L}$ in herbal medicine and its interaction with disc antibiotics. BMC Complementary and Alternative Medicine 9: 37-37.

Pfaller, M.A., Diekema, D.J., Gibbs, D.L., Newell, V.A., Ellis, D., Tullio, V., Rodloff, A., Fu, W., Ling, T.A. 2010. Results from the ARTEMIS DISK global antifungal surveillance study, 1997 to 2007: a 10.5-year analysis of susceptibilities of Candida species to fluconazole and voriconazole as determined by CLSI standardized disk diffusion. Journal of Clinical Microbiology 48(4): 1366-1377.

Pinto, E., Vale-Silva, L., Cavaleiro, C., Salgueiro, L. 2009. Antifungal activity of the clove essential oil from Syzygium aromaticum on Candida, Aspergillus and dermatophyte species. Journal of Medical Microbiology 58(11): 1454-1462.

Rosato, A., Vitali, C., Gallo, D., Balenzano, L., Mallamaci, R. 2008. The inhibition of Candida 
species by selected essential oils and their synergism with amphotericin B. Phytomedicine 15(8): 635-638. Sagué, C.M.B., Jarvis, W.R., System, N.N.I.S. 1993. Secular trends in the epidemiology of nosocomial fungal infections in the United States, 1980-1990. The Journal of Infectious Diseases 167(5): 1247-1251. Sakaue, Y., Domon, H., Oda, M., Takenaka, S., Kubo, M., Fukuyama, Y., Okiji, T., Terao, Y. 2016. Anti-biofilm and bactericidal effects of magnolia bark-derived magnolol and honokiol on Streptococcus mutans. Microbiology and Immunology 60(1): $10-16$.

Seal, T. 2016. Quantitative HPLC analysis of phenolic acids, flavonoids and ascorbic acid in four different solvent extracts of two wild edible leaves, Sonchus arvensis and Oenanthe linearis of North-Eastern region in India. Journal of Applied Pharmaceutical Science 6(02): 157-166.

Shan, B., Cai, Y.Z., Sun, M., Corke, H. 2005. Antioxidant capacity of 26 spice extracts and characterization of their phenolic constituents. Journal of Agricultural and Food Chemistry 53(20): 7749-7759.

Shen, C.-C., Ni, C.-L., Shen, Y.-C., Huang, Y.-L., Kuo, C.-H., Wu, T.-S., Chen, C.-C. 2009. Phenolic constituents from the stem bark of Magnolia officinalis. Journal of Natural Products 72(1): 168-171.

Shen, J.-L., Man, K.-M., Huang, P.-H., Chen, W.-C., Chen, D.-C., Cheng, Y.-W., Liu, P.-L., Chou, M.-C., Chen, Y.-H. 2010. Honokiol and magnolol as multifunctional antioxidative molecules for dermatologic disorders. Molecules (Basel, Switzerland) 15(9): 6452-6465.

Shi, C., Zhang, X., Sun, Y., Yang, M., Song, K., Zheng, Z., Chen, Y., Liu, X., Jia, Z., Dong, R., Cui, L., Xia, X. 2016. Antimicrobial activity of ferulic acid against Cronobacter sakazakii and possible mechanism of action. Foodborne Pathogens and
Disease 13(4): 196-204.

Shobana, S., Akhilender Naidu, K. 2000. Antioxidant activity of selected Indian spices. Prostaglandins, Leukotrienes and Essential Fatty Acids 62(2): 107-110.

Silva, I.C.G.d., Santos, H.B.d.P., Cavalcanti, Y.W., Nonaka, C.F.W., Sousa, S.A.d., Castro, R.D.d. 2017. Antifungal activity of eugenol and its association with nystatin on Candida albicans. Brazilian Research in Pediatric Dentrtry and Integrated Clinic 17(1): e3235.

Singh, A.K., Dhamanigi, S.S., Asad, M. 2009. Anti-stress activity of hydro-alcoholic extract of Eugenia caryophyllus buds (clove). Indian journal of pharmacology 41(1): 28-31.

Sobel, J.D. 2007. Vulvovaginal candidosis. The Lancet 369(9577): 1961-1971.

Sugar, A.M., Hitchcock, C.A., Troke, P.F., Picard, M. 1995. Combination therapy of murine invasive candidiasis with fluconazole and amphotericin B. Antimicrobial Agents and Chemotherapy 39(3): 598-601.

Sun, L.-M., Liao, K., Liang, S., Yu, P.-H., Wang, D.-Y. 2015. Synergistic activity of magnolol with azoles and its possible antifungal mechanism against Candida albicans. Journal of Applied Microbiology 118(4): 826-838.

Tampieri, M.P., Galuppi, R., Macchioni, F., Carelle, M.S., Falcioni, L., Cioni, P.L., Morelli, I. 2005. The inhibition of Candida albicans by selected essential oils and their major components. Mycopathologia 159(3): 339-345.

Taveira, G.B., Carvalho, A.O., Rodrigues, R., Trindade, F.G., Da Cunha, M., Gomes, V.M. 2016. Thionin-like peptide from Capsicum annuum fruits: mechanism of action and synergism with fluconazole against Candida species. BMC Microbiology 16(1): 12. Vaijayanthimala, J., Anandi, C., Udhaya, V., Pugalendi, K.V. 2000. Anticandidal activity of certain South 
Indian medicinal plants. Phytotherapy Research 14(3): 207-209.

Wagner, H., Ulrich-Merzenich, G. 2009. Synergy research: Approaching a new generation of phytopharmaceuticals. Phytomedicine 16(2): 97-110.

Wan, C., Li, P., Chen, C., Peng, X., Li, M., Chen, M., Wang, J., Chen, J. 2017. Antifungal activity of Ramulus cinnamomi explored by ${ }^{1} \mathrm{H}-\mathrm{NMR}$ based metabolomics approach. Molecules (Basel, Switzerland) 22(12): 2237.

Whaley, S.G., Berkow, E.L., Rybak, J.M., Nishimoto, A.T., Barker, K.S., Rogers, P.D. 2017. Azole antifungal resistance in Candida albicans and emerging non-albicans Candida species. Frontiers in Microbiology 7(2173).

Xiang, M.-J., Liu, J.-Y., Ni, P.-H., Wang, S., Shi, C., Wei, B., Ni, Y.-X., Ge, H.-L. 2013. Erg11 mutations associated with azole resistance in clinical isolates of Candida albicans. FEMS Yeast Research 13(4): 386-393.

Zhao, Y., Stensvold, C.R., Perlin, D.S., Arendrup, M.C. 2013. Azole resistance in Aspergillus fumigatus from bronchoalveolar lavage fluid samples of patients with chronic diseases. Journal of Antimicrobial Chemotherapy 68(7): 1497-1504.

Zhou, P., Fu, J., Hua, H., Liu, X. 2017. In vitro inhibitory activities of magnolol against Candida spp. Drug Design, Development and Therapy 11: 2653-2661. 